\title{
CARACTERÍSTICAS FISIOLÓGICAS E CRESCIMENTO DE CLONES DE EUCALIPTO EM RESPOSTA AO BORO ${ }^{1}$
}

\author{
Edson Marcio Mattiello², Hugo Alberto Ruiz ${ }^{3}$, Ivo Ribeiro da Silva ${ }^{3}$, Patrícia de Carvalho Guerra ${ }^{4}$ e \\ Vinícius Molica de Andrade ${ }^{4}$
}

\begin{abstract}
RESUMO - A exigência para boro (B) varia largamente entre e dentro das espécies vegetais. Objetivando avaliar a resposta de clones de eucalipto ao B em solução nutritiva foi realizado ensaio em casa de vegetação com oito clones. As plantas cresceram em soluções nutritivas com 0, 10, 20, 50 e $100 \mu \mathrm{mol} / \mathrm{L}$ de B, durante 70 dias. Na finalização do ensaio determinaram-se características fisiológicas, produção de matéria seca e teores de B no tecido vegetal. Houve resposta diferenciada dos clones à concentração de B na solução nutritiva, com máxima produção de matéria seca entre 28 e $69 \mu \mathrm{mol} / \mathrm{L}$ de B. Em baixas concentrações de B, pôde-se observar sintomas visuais de deficiência e, em altas concentrações, não foram observados sintomas de toxidez, porém houve redução na produção de matéria seca. A resposta do eucalipto ao B na solução nutritiva depende do clone, havendo diferenças entre eles na tolerância à deficiência e toxidez e na eficiência de utilização de B. Os clones 68 e 129 apresentaram as mais elevadas taxas de fotossíntese. O clone 3487 foi o mais responsivo ao B. Os clones 3487, 3336 e 68 foram mais sensíveis à deficiência e os clones 3281 e 1270 os mais tolerantes à deficiência. O clone 2486 foi o mais sensível à toxidez e o clone 3281 o mais tolerante. Os clones 3487 , 2486 e 129 foram mais eficientes na utilização de B.
\end{abstract}

Palavras-chave: Eucalyptus sp, deficiência e CUB.

\section{PHYSIOLOGICAL CHARACTERISTICS AND DRY MATTER PRODUCTION OF EUCALYPTUS IN RESPONSE TO BORON}

\begin{abstract}
Boron $(B)$ requirement for plant growth varies both within and among plant species. In order to evaluate the response of clones of eucalyptus to B in nutrient solution, an experiment was carried out under glasshouse conditions, with eight clones. Plants were grown in nutrient solutions at B concentrations of 0, 10, 20, 50 and $100 \mu \mathrm{mol} / \mathrm{L}$ for 70 days, after which, physiological variables, dry matter production and boron content were determined. There was a differential response of the eucalyptus clones to the concentration of boron in nutrient solution with maximum dry matter production occurring between 28 and $68 \mu \mathrm{mol} / \mathrm{L}$ of $B$ in nutrient solution. At low concentrations of $B$, visual symptoms of deficiency were observed. At high $B$ concentrations, toxicity symptoms were not observed; however, there was a reduction in dry matter production. The response to $B$ depends on the clone. The clones 129 and 68 showed the highest rates of photosynthesis. The clone 3487 was the most responsive to $B$. The clones 3487,3336 and 68 were more sensitive to $B$ deficiency whereas clones 3281 and 1270 exhibited greater tolerance to B deficiency. Clone 2486 was the most sensitive to B toxicity and the clone 3281 showed the highest tolerance to B. Clones 3487, 2486 and 129 were more efficient in the use of boron.
\end{abstract}

Keywords: Eucalyptus sp., deficiency and NUE.

\footnotetext{
${ }^{1}$ Recebido em 28-01-2008 e aceito para publicação em 23.06.2009.

${ }^{2}$ Vale Florestar. Dom Eliseu, PA - Brasil. E-mail: <mattielloem@yahoo.com.br>.

${ }_{3}^{3}$ Departamento de Solos da Universidade Federal de Viçosa (UFV). E-mail: <hruiz@ufv.br>e <ivosilva@ufv.br>.

${ }^{4}$ Graduando em Agronomia. Universidade Federal de Viçosa, UFV, Viçosa - MG. E-mail: <paty_solos@yahoo.com.br>e <viniciusmolica@yahoo.com.br>.
} 


\section{INTRODUÇÃO}

O boro é, entre os micronutrientes, aquele que mais freqüentemente apresenta deficiência no solo, requerendo repetidas adubações com esse elemento. A exigência de B varia largamente entre as espécies vegetais (BELL, 1997; KOZLOWSKIe PALLARDY, 1997). Há evidências de que o grau de exigência e sensibilidade à deficiência a $\mathrm{B}$ está intimamente relacionado com o teor de pectina da parede celular. Assim, espécies com parede celular rica em pectina, como as dicotiledôneas, apresentam maior requerimento de B quando comparadas com gramíneas que possuem parede celular com menor teor de pectina (HU et al., 1996).

No Brasil, solos deficientes em B são encontrados em várias regiões, com destaque para o Cerrado, onde o cultivo do eucalipto tem-se expandido. Entre outros autores, Sgarbi et al. (1999) mostraram que a deficiência de B é uma das mais limitantes ao crescimento do eucalipto na fase jovem.

Em estudo exploratório, Andrade et al. (1995) verificaram que a susceptibilidade à deficiência de $B$ e à seca dos ponteiros apresentava a seqüência: E. globulus $>$ E. dunii $>$ E. urophylla $>$ E. camaldulensis. As diferenças no requerimento de B por essas espécies estavam, possivelmente, associadas à eficiência nutricional específica para o elemento. Essa maior eficiência pode ser devida a diferentes mecanismos: habilidade na aquisição de B do solo ou do meio de crescimento, formas de absorção do nutriente e distribuição na planta e, ou, habilidade na utilização do elemento (PERKASEM e JAMJOD, 1997).

A adubação e nutrição florestal têm assumido papel importante na obtenção de maiores produtividades no setor florestal brasileiro. A constatação de exigências nutricionais diferenciadas dos materiais genéticos (espécies ou clones) pode contribuir para melhor dimensionamento das áreas de plantio. A melhor alocação de clones nessas áreas, considerando suas exigências nutricionais e, ou, a tolerância a possíveis deficiências, é uma estratégia de otimização do sistema de produção. Adicionalmente, em espécies florestais, com ciclos mais longos que as anuais, esses requerimentos nutricionais distintos, sempre que possível, devem ser avaliados numa fase o mais jovem possível, pois também forneceriam informações complementares para os programas de seleção e melhoramento.
Neste trabalho, objetivou-se avaliar a resposta de oito clones de eucalipto, na fase de mudas, à concentração de B em solução nutritiva, visando distingui-los e selecionar genótipos mais resistentes a baixas concentrações do nutriente.

\section{MATERIAL E MÉTODOS}

Oito clones de eucalipto (Empresa 1-68 e 129 e Empresa 2- 1270, 2486, 3281, 3334, 3336 e 3487) foram selecionados. O clone 68 foi inicialmente selecionado no litoral do ES no da BA, pois apresenta expressivo crescimento vegetativo em condições mais favoráveis de crescimento. O clone 129 foi selecionado na região de Belo Oriente, MG e apresenta maior tolerância a limitações edafoclimáticas, quando comparado com o clone 68. Os clones da empresa 2 são largamente plantados na região do Cerrado brasileiro onde a deficiência de B tem se mostrado mais limitante à produtividade de eucalipto. As mudas foram propagadas via microestaquia e, aos 30 dias, removidas dos tubetes, lavando-se cuidadosamente as raízes com água destilada para a retirada do substrato. Essas mudas foram inicialmente colocadas em bandejas plásticas contendo 30 L de solução nutritiva de Clark (CLARK, 1975), 1² força, durante um período de 21 dias para adaptação e formação do sistema radicular. Essa solução continha $10 \mu \mathrm{mol} / \mathrm{L}$ de B. Após esse período, as raízes das plantas foram lavadas por três vezes em água destilada e transferidas para bandejas plásticas contendo soluções nutritivas com concentrações de 0, 10, 20, 50 e 100 $\mu \mathrm{mol} / \mathrm{L}$ de B, mantendo-se nessas condições por 70 dias.

O delineamento experimental utilizado foi de blocos casualizados, num esquema de parcelas sub-divididas. As parcelas foram compostas pelas concentrações de $\mathrm{B}$ na solução nutritiva e as subparcelas, pelos clones. $\mathrm{O}$ ensaio contou com quatro repetições, sendo uma planta por repetição. As plantas foram mantidas sob arejamento constante, e o pH da solução foi ajustado diariamente a 5,5. A troca da solução nutritiva foi feita, inicialmente, a cada 15 dias (0-15 d), a cada 10 dias na fase intermediária (16-45 d) e, na fase final (46-70 d), a cada oito dias, de modo a manter as concentrações de B e demais nutrientes, o mais constante possível.

No decorrer do ensaio, as plantas foram observadas diariamente, anotando-se o dia em que apresentaram os primeiros sintomas de deficiência ou possível toxidez. Previamente à coleta das plantas quantificaram-se 
características fisiológicas, como fotossíntese (A), condutância estomática (Gs), transpiração (E) e a razão das concentrações interna e externa de $\mathrm{CO}_{2}$ (ci:ca), com auxílio de um analisador portátil de gases no infravermelho (IRGA, modelo LI 6400, Licor). As determinações foram feitas no período compreendido entre oito e onze horas, no terceiro par de folhas a partir do ápice dos ramos.

As plantas foram coletadas 70 dias após a aplicação dos tratamentos, separando-se as raízes, o caule, as folhas maduras e as folhas jovens (até o terceiro par, a partir do ápice dos ramos). Todo o material foi levado à estufa de circulação forçada de ar, a $65^{\circ} \mathrm{C}$, por um período de $72 \mathrm{~h}$, quantificando-se, por meio de pesagem, a produção de matéria seca das diferentes partes.

O material seco foi moído ( $<5 \mathrm{~mm}$ ) em moinho Wiley. Aproximadamente, $0,25 \mathrm{~g}$ foram calcinados por $3 \mathrm{~h}$ a $550^{\circ} \mathrm{C}$ em cadinhos de porcelana e, em seguida, o resíduo foi dissolvido em $10 \mathrm{~mL}$ de ácido clorídrico, na concentração de $0,1 \mathrm{~mol} / \mathrm{L}$. O resíduo foi passado por filtro de $0,45 \mu \mathrm{m}$ e armazenado em recipientes plásticos. Os teores de B no tecido vegetal foram quantificados por colorimetria, pelo método da Azometina-H.

Os dados das características avaliadas foram analisados estatisticamente pelo programa SAS (SAS Institute Inc., Cary, NC, 2004). Para cada clone, ajustaram-se equações de regressão, considerando a concentração de B em solução nutritiva como variável independente. Os coeficientes das equações de regressão foram testados pelo teste t, utilizando-se o quadrado médio e graus de liberdade do resíduo resultantes da combinação dos quadrados médios e graus de liberdade do resíduo das parcelas e das subparcelas da Anova. Foram estimadas as concentrações de B em solução nutritiva necessárias para obtenção da máxima produção de matéria seca de cada clone, sendo a produção de matéria seca de parte aérea (MSPA) tomada como referência. A partir dos modelos definidos para cada clone, foram calculados os incrementos e decréscimos na produção de MSPA. $\mathrm{O}$ incremento foi resultante da diferença dos valores estimados no ponto de máxima produção de MSPA e a MSPA na dose de $0 \mu \mathrm{mol} / \mathrm{L}$ de B; e o decréscimo refere-se à diferença da produção de MSPA entre o ponto de máxima produção e a MSPA na dose de 100 $\mathrm{mmol} / \mathrm{L}$ de B. Para comparar a produção de MSPA, foram calculados valores relativos, atribuindo-se 100/100 à maior média ajustada. O coeficiente de utilização biológico de B (CUB-B) refere-se à matéria seca produzida por unidade do nutriente. Assim, o CUB-B foi obtido pela equação CUB-B $=1 /$ Teor de B*1000000 $(\mathrm{kg} / \mathrm{kg})$, adotando-se como referência os teores estimados de B no tecido vegetal correspondentes aos pontos de máxima produção de MSPA.

\section{RESULTADOS E DISCUSSÃO}

Vinte e cinco dias após a aplicação dos tratamentos, observaram-se sintomas visuais típicos de deficiência de B nas plantas crescidas na ausência do nutriente. Algumas plantas apresentaram clorose nas folhas jovens, seguida de encarquilhamento, tornando-as facilmente quebradiças. O caule das plantas deficientes em B apresentaram maior rigidez, com aspecto de vitrificação, quebrando-se facilmente. Esses sintomas corroboram observações de campo em que o efeito do vento em áreas com deficiência de B é muito mais acentuado, com quedas de árvores e quebra de galhos e caules. O clone 3487 foi o primeiro a apresentar esses sintomas, seguido pelo clone 3336. Não foram observados sintomas visuais de toxidez de $\mathrm{B}$, mesmo na maior concentração utilizada, de $100 \mu \mathrm{mol} / \mathrm{L}$ de $\mathrm{B}$.

De modo geral, as equações que permitiram o melhor ajuste para os valores da taxa fotossintética, da condutância estomática e da transpiração foram as do modelo raiz quadrática (Figura 1). Tanto a deficiência (dose de $0 \mathrm{mmol} / \mathrm{L}$ de B) quanto as concentrações mais elevadas de $\mathrm{B}$ reduziram as trocas gasosas das plantas de eucalipto. Não foram obtidos ajustes de modelos lineares que descrevessem as respostas dos clones 1270 e 3281. Assim, os valores médios desses dois clones foram, respectivamente, de 12,35 e $12,54 \mu \mathrm{mol} / \mathrm{m}^{2} / \mathrm{s}$ de $\mathrm{CO}_{2}$ para A; de 0,390 e $0,394 \mathrm{~mol} / \mathrm{m}^{2} / \mathrm{s}$ de $\mathrm{H}_{2} \mathrm{O}$ para gs; e de 5,87 e $6,77 \mathrm{mmol} / \mathrm{m}^{2} / \mathrm{s} \mathrm{de} \mathrm{H}_{2} \mathrm{O}$ para E. Sob deficiência de $\mathrm{B}$, esses materiais apresentaram elevados valores de $\mathrm{A}$, gs e $\mathrm{E}$ e resposta nula quando o nutriente foi acrescentado no meio de cultivo. Para todos os clones, a razão ci:ca manteve-se constante com o incremento da concentração de B na solução nutritiva (Figura 1).

Os clones 68 e 129 foram os que apresentaram, em geral, os maiores valores de fotossíntese, transpiração e condutância estomática, exceto na dose de $0 \mu \mathrm{mol} / \mathrm{L}$ de B (Figura 1). Essa resposta sugere alto potencial desses clones para a produção de matéria seca quando o nutriente não é limitante, fato não observado no ensaio, possivelmente em conseqüência do curto período experimental. Os demais clones apresentaram desempenho

R. Árvore, Viçosa-MG, v.33, n.5, p.821-830, 2009 
intermediário em relação às características fisiológicas avaliadas. Os clones 3336, 2486 e 3487 exibiiram alta sensibilidade das características fisiológicas sob deficiência de $\mathrm{B}$ e foram altamente responsivos quando o B foi adicionado ao meio de cultivo (Figura 1).

A deficiência nutricional afeta o transporte de água das raízes para a parte aérea das plantas (CLARKSON et al., 2000). A deficiência de B reduz a permeabilidade da membrana plasmática e o fluxo de água, afetando a absorção dos nutrientes. A redução da condutância hidráulica do xilema pode estar associada à menor transpiração, absorção de B e crescimento de plantas deficientes sob deficiência de B (NABLE et al., 1997; DANNEL et al., 1998). O papel estrutural do B e aqueles associados às funções de divisão, diferenciação e alongamento celular devem estar associados com a alteração do potencial hidráulico da planta (NABLE et al., 1997; DANNEL et al., 1998).
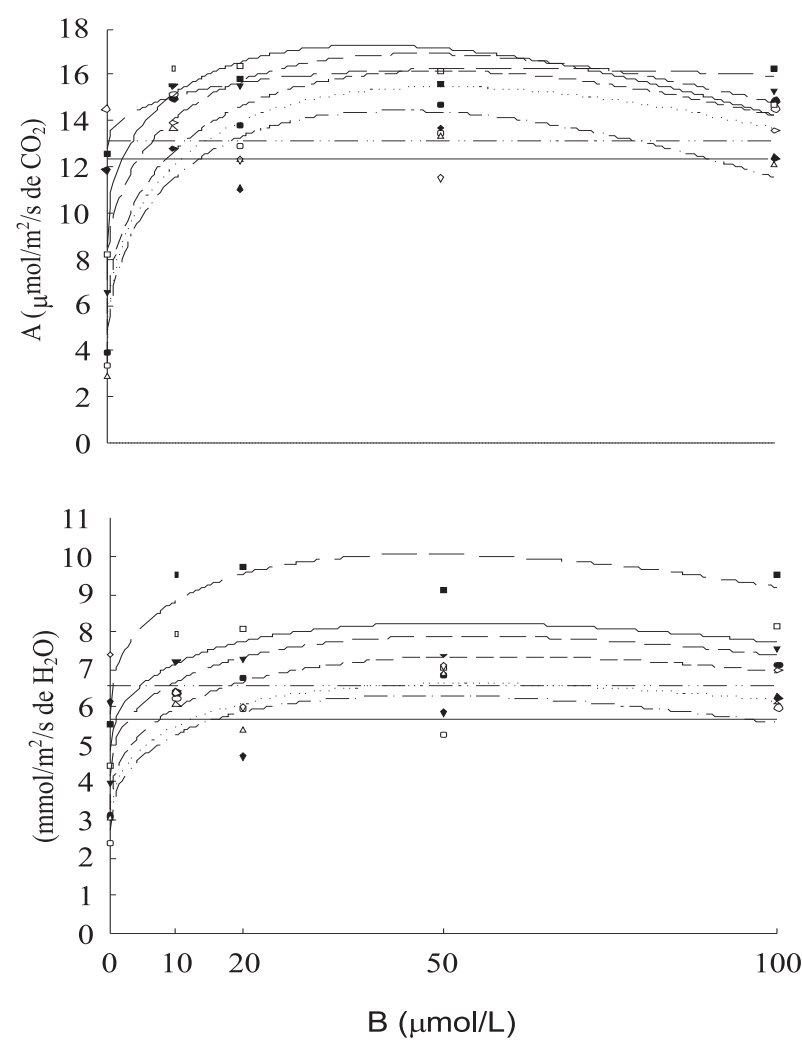

A redução da condutância estomática das plantas pode levar à redução da fotossíntese, pois os estômatos constituem a principal barreira na assimilação de $\mathrm{CO}_{2}$. No entanto, os valores da razão ci:ca permaneceram praticamente inalterados nas diferentes doses de B, mostrando que o substrato $\left(\mathrm{CO}_{2}\right)$ não era limitante para a fotossíntese (Figura 1). Embora não existam evidências da participação direta do B na fotossíntese, é de se esperar que as funções do B na biossíntese da parede celular e no metabolismo de carboidratos (CAKMAKe RÖMHELD, 1997), na síntese de polifenóis (BLEVINS e LUKASZEWSKI, 1998), no transporte de açúcares através de membranas (TAIZ e ZIEGER, 2004), nos fitormônios (LI et al., 2001), na síntese de ácidos nucléicos (DNA e RNA), na formação de pectinas e divisão celular (DECHEN et al., 1991) e no potencial hídrico e abertura estomática (SHARMA e RAMCHANDRA, 1990) possam estar associados à redução da fotossíntese e conseqüente redução na produção de matéria seca observada em plantas deficientes em B.
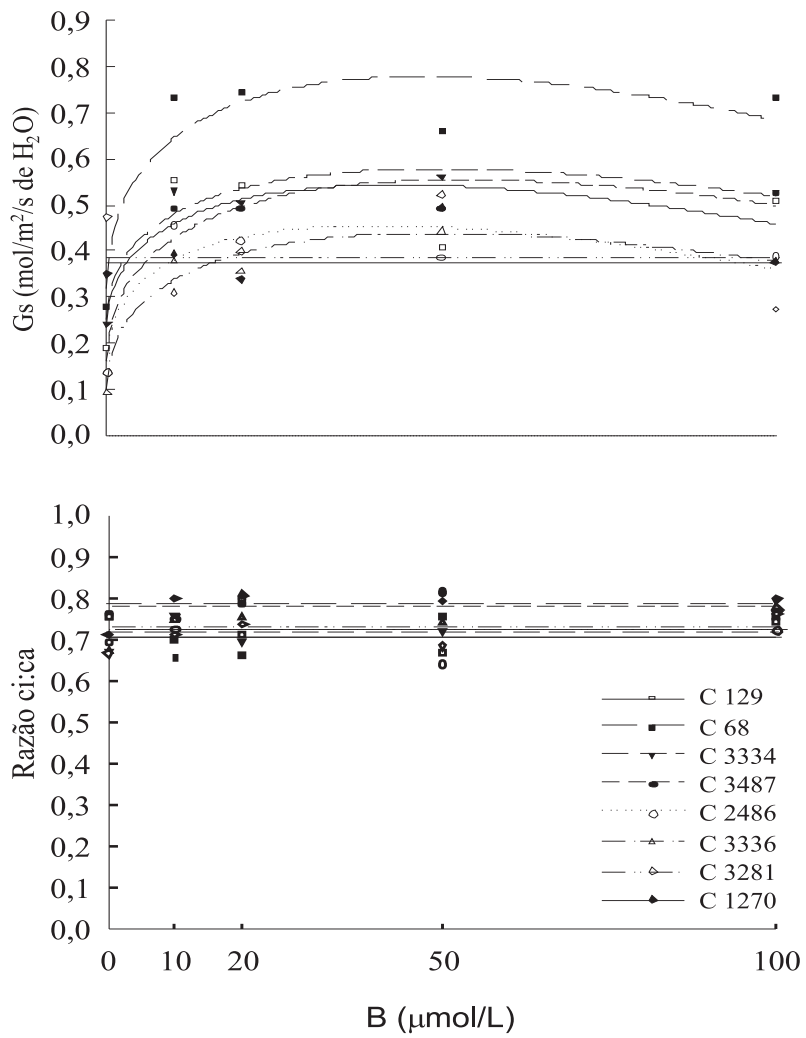

Figura 1 - Fotossíntese (A), condutância estomática (Gs), transpiração (E) e razão ci:ca dos clones de eucalipto, considerando a concentração de B na solução nutritiva.

Figure 1 - Photosynthesis (A) stomatal conductance (Gs), transpiration (E) and ci:ca ratio of eucalyptus clones, considering $B$ concentration in nutrients solution.

R. Árvore, Viçosa-MG, v.33, n.5, p.821-830, 2009 
A produção de matéria seca de raízes, caules e folhas mostrou-se diferenciada entre os clones de eucalipto em resposta às concentrações de $\mathrm{B}$ na solução nutritiva (Tabela 1). Como previamente indicado, as plantas não apresentaram sintomas visuais de toxidez de B nas concentrações mais elevadas. Não obstante, o ajuste das médias ao modelo raiz quadrada, com o ponto de máxima produção dentro do intervalo experimental, indica resposta negativa às maiores concentrações de B na solução nutritiva, sugerindo a ocorrência de efeitos deletérios nas plantas sob estas concentrações.

Verificou-se que os clones, na seqüência $3487>68>3336$, foram os mais sensíveis à ausência de B (dose zero), apresentando menores produções de MSPA. A resposta dos materias genéticos mostrou-se distinta entre os componentes da planta. Os clones 3281 e 1270, corroborando com os valores de fotossíntese (Figura 1), apresentaram maiores produções de MSPA em condição de deficiência de $\mathrm{B}$, enquanto o clone 3334 destacou-se na produção de MSR. O clone 3487 destacou-se na produção de matéria seca de parte aérea com a presença de B na solução nutritiva, demonstrando ser um material altamente responsivo ao nutriente. A produção de MSPA do clone 3281 manteve-se constante em concentrações superiores a $10 \mu \mathrm{mol} / \mathrm{L}$ de B, sem evidência de toxidez até a concentração de $100 \mu \mathrm{mol} / \mathrm{L}$ de B. O clone 2486 atingiu máxima produção de MSPA em baixa concentração de B, porém, ao contrário do clone 3281, apresentou acentuada redução na produção

Tabela 1 - Produção de matéria seca da parte aérea e raízes, estimativa da máxima produção de MSPA (Y ${ }_{\max }$ ), estimativa da concentração de $\mathrm{B}$ na solução nutritiva para obtenção de $\mathrm{Y}_{\max }\left(\mathrm{X}_{\mathrm{Ymax}}\right)$ e incremento e decréscimo na produção de MSPA dos clones de eucalipto, considerando a concentração de B na solução nutritiva.

Table 1 - Dry matter production of shoots and roots, estimate of maximum production of MSPA ( $\left.Y_{\max }\right)$, estimate of boron concentration in nutrients solution to obtain $Y_{\max }\left(X_{Y \max }\right)$ and increase and decrease in MSPA production of eucalyptus clones, considering the $B$ concentration in the nutrient solution.

\begin{tabular}{|c|c|c|c|c|c|c|c|c|}
\hline \multirow[t]{2}{*}{ Concentrações } & \multicolumn{8}{|c|}{ Clones } \\
\hline & 68 & 129 & 1270 & 2486 & 3281 & 3334 & 3336 & 3487 \\
\hline $\mathrm{B}(\mu \mathrm{mol} / \mathrm{L})$ & \multicolumn{8}{|c|}{$\begin{array}{l}\text { Matéria seca de parte aérea } \\
\text { g/planta }\end{array}$} \\
\hline 0 & 5,76 & 8,53 & 12,56 & 10,74 & 13,49 & 10,40 & 6,43 & 4,36 \\
\hline 10 & 11,33 & 17,59 & 21,89 & 23,80 & 31,66 & 20,29 & 20,19 & 40,77 \\
\hline 20 & 13,48 & 20,76 & 27,19 & 25,24 & 24,36 & 26,33 & 21,31 & 28,74 \\
\hline 50 & 10,09 & 17,13 & 25,21 & 21,14 & 22,09 & 25,89 & 24,81 & 34,05 \\
\hline 100 & 9,34 & 13,06 & 22,54 & 14,89 & 29,38 & 24,66 & 17,40 & 38,36 \\
\hline$Y \max (g /$ planta $)$ & 12,35 & 19,66 & 26,55 & 24,81 & 26.87 & 26,83 & 24,05 & 39,53 \\
\hline$X_{Y \max }(\mu \mathrm{mol} / \mathrm{L}$ de B $)$ & 32 & 30 & 41 & 28 & 45 & 52 & 39 & 55 \\
\hline $\mathbf{R}^{2(1)}$ & 0,812 & 0,939 & 0,949 & 0,951 & 0,802 & 0,964 & 0,984 & 0,746 \\
\hline
\end{tabular}

\begin{tabular}{|c|c|c|c|c|c|c|c|c|}
\hline \multirow[b]{2}{*}{0} & \multicolumn{8}{|c|}{ g/planta } \\
\hline & 1,43 & 1,39 & 2,36 & 1,80 & 1,99 & 2,49 & 1,24 & 1,07 \\
\hline 10 & 2,46 & 3,37 & 3,75 & 4,72 & 5,54 & 4,94 & 4,02 & 8,02 \\
\hline 20 & 2,96 & 4,29 & 4,78 & 4,94 & 5,14 & 5,99 & 4,30 & 6,34 \\
\hline 50 & 2,39 & 3,45 & 5,04 & 4,20 & 4,47 & 6,06 & 5,69 & 7,00 \\
\hline 100 & 1,80 & 2,34 & 4,42 & 2,53 & 5,40 & 5,63 & 4,00 & 8,83 \\
\hline$Y \max (\mathrm{g} / \mathrm{planta})$ & 2,75 & 3,98 & 4,92 & 4,92 & 5,41 & 6,23 & 5,16 & 8,50 \\
\hline $\mathrm{X}_{\mathrm{Ymax}}(\mu \mathrm{mol} / \mathrm{L}$ de $\mathrm{B})$ & 28 & 30 & 50 & 27 & 45 & 50 & 45 & 68 \\
\hline $\mathrm{R}^{2(1)}$ & 0,918 & 0,943 & 0,956 & 0,970 & 0,792 & 0,986 & 0,951 & 0,794 \\
\hline
\end{tabular}

Incremento na produção de $\mathrm{MSPA}^{(2)}$

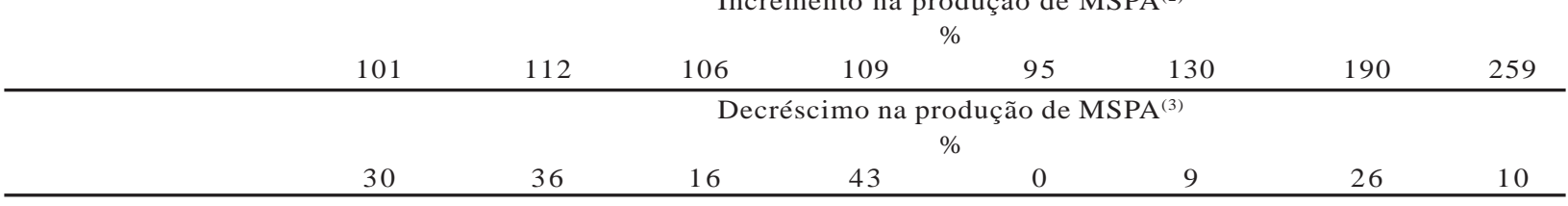

(1) Ajuste ao modelo de regressão raiz quadrada, exceto o clone 3281 , ajustado ao modelo y=a+be ${ }^{-x}$. Todos os coeficientes são significativos a pelo menos $5 \%$ de probabilidade pelo test $\mathrm{t}$, exceto o clone $68 ;{ }^{(2)}$ Incremento na produção de MSPA entre a concentração $0 \mu$ mol/L de $\mathrm{B}$ e $\mathrm{X}_{\mathrm{Ymax}} ;{ }^{(3)}$ Decréscimo na produção de MSPA entre $\mathrm{X}_{\mathrm{Ymax}}$ e a concentração de $100 \mu \mathrm{mol} / \mathrm{L}$ de B. 
de MSPA em maiores concentrações de B. Os clones 129 e 68 apresentaram a menor produção de MSPA entre os clones estudados, sendo este último o inferior (Figura 2).

A concentração externa de B na solução nutritiva para obtenção da máxima produção de matéria seca foi de 24 a $69 \mu \mathrm{mol} / \mathrm{L} \mathrm{de} \mathrm{B,} \mathrm{com} \mathrm{média} \mathrm{de} 40 \mu \mathrm{mol} / \mathrm{L}$ de B (Tabela 1). O clone 3487 apresentou maior demanda por B, enquanto os clones 2486, 68 e 129 foram menos exigentes. Essa amplitude mostra que o melhoramento genético das espécies de eucalipto e a consequiente obtenção de clones híbridos resultantes desse processo podem proporcionar ampliação na faixa de utilização de $\mathrm{B}$, tradicionalmente conhecida como estreita entre os limites deficiente, ótimo e tóxico. Como mencionado anteriormente, não foram observados sintomas visuais de toxidez de B, mesmo na dose de $100 \mu \mathrm{mol} / \mathrm{L}$ desse nutriente.

Os níveis críticos externos de $\mathrm{B}$ requiridos por eucalyptus sp. diferem largamente na literatura. Asad et al. (2001) relatam níveis críticos externos para $E$. calophylla de 0,8 e 1,2 $\mu \mathrm{mol} / \mathrm{L}$ de B aos 20 e 40 dias após o transplante, respectivamente. Sakya et al. (2002) mencionaram nível crítico em E. globulus, cultivado por 21 dias em solução nutritiva, de 1,08 e 0,99 $\mu \mathrm{mol} /$ L de B para parte aérea e nas raízes, respectivamente. Concentrações de B em solução nutritiva, associadas a máxima produção de matéria seca aos 114 dias após o transplante, foram de 4,07; 4,5; 8,88; e 9,25 $\mu \mathrm{mol} /$

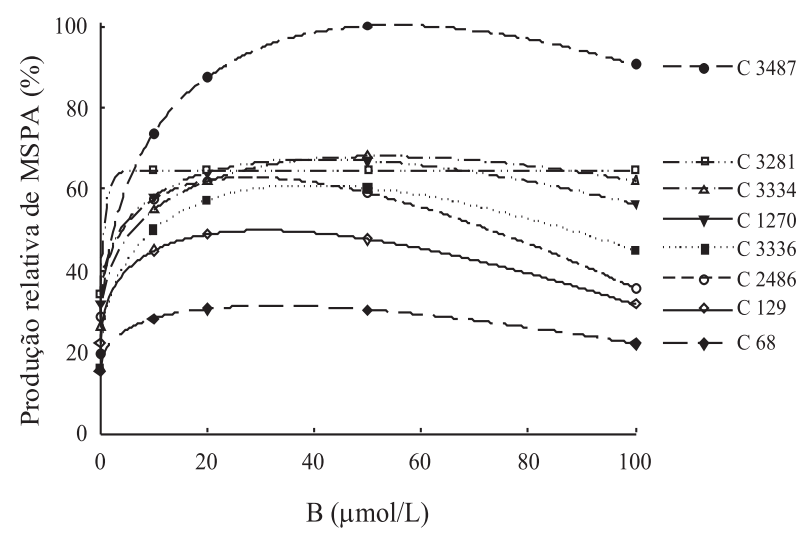

Figura 2 - Produção relativa de matéria seca de parte aérea dos clones de eucalipto, considerando a concentração de B na solução nutritiva.

Figure 2 - Shoot relative dry matter production of eucalyptus clones, considering B concentration in nutrient solution.
L de B em E. camaldulensis, E. urophylla, E. dunnii $e$ E. globulus, respectivamente (ANDRADE et al., 1995). Novelino et al. (1982) encontraram níveis críticos de 1,$85 ; 9,25 ;$ e $46,45 \mu \mathrm{mol} / \mathrm{L}$ de B para E. camaldulensis, E. citriodora e E. paniculata, respectivamente, cultivados por 74 dias em solução nutritiva. Possivelmente, a exigência diferenciada das espécies, o método de cultivo e a idade das plantas são as principais razões para tal fato.

O clone 3487 apresentou o maior incremento na produção de MSPA (259\%), seguido dos clones 3336 (190\%) e 3334 (130\%) (Tabela 1). Isso indica que esses materiais genéticos são altamente responsivos ao B na solução nutritiva e, possivelmente, tiveram maior demanda por fertilização com B em condições de campo. Os clones 3281 e 68 apresentaram os menores incrementos na produção de matéria seca de parte aérea, 95 e $101 \%$, respectivamente. Os demais clones apresentaram desempenho intermediário, com incrementos de 106 a $112 \%$ (Tabela 1).

O clone 2486 apresentou-se mais sensível à toxidez de B, com decréscimo de $43 \%$ na produção de MSPA, na concentração de $100 \mu \mathrm{mol} / \mathrm{L}$ de B. Os clones 129 e 68 apresentaram reduções de 36 e $30 \%$, respectivamente. Ao contrário, o clone 3281 não apresentou redução na produção de matéria seca nas concentrações mais elevadas, demostrando maior tolerância à toxidez de B (Tabela 1).

Os teores de B no tecido vegetal aumentaram com o incremento da concentração de B em solução nutritiva (Tabela 2). Em média, o aumento no teor de B nas raízes foi de 17,77 para $72,83 \mathrm{mg} / \mathrm{kg}$; no caule, de 9,92 para $19,55 \mathrm{mg} / \mathrm{kg}$; nas folhas maduras, de 2,7 para $74,39 \mathrm{mg} / \mathrm{kg}$; e nas folhas jovens, de 3,83 para $46,84 \mathrm{mg} / \mathrm{kg}$, quando se aumentou a dose de 0 para $100 \mu \mathrm{mol} / \mathrm{L}$ de B. Os teores de B nos clones crescidos na concentração de $0 \mu \mathrm{mol} / \mathrm{L}$ de B variaram de 14,48 a $22,18 \mathrm{mg} / \mathrm{kg}$ nas raízes, de 8,34 a $11,37 \mathrm{mg} / \mathrm{kg}$ no caule, de 1,86 a $3,88 \mathrm{mg} / \mathrm{kg}$ nas folhas maduras e de 2,92 a $6,01 \mathrm{mg} / \mathrm{kg}$ nas folhas jovens. A menor variação no teor de B foi observado no caule, e a maior, nas folhas maduras, como era de se esperar, pois a translocação e redistribuição de $\mathrm{B}$ nos tecidos é fortemente influenciada pelo fluxo transpiracional (BROW e SHELP, 1997).

Os teores de B estimados, correspondentes aos pontos de máxima produção de MSPA, apresentaram variações entre os clones de até 37, 22, 34 e $29 \%$, com 
média de 47, 19, 62 e 46 mg/kg, nas raízes, caules, folhas maduras e folhas jovens, respectivamente (Tabela 2). Em condições de suprimento adequado de B, os teores foliares de B decresceram das folhas maduras para as folhas novas, possivelmente devido à maior transpiração das folhas maduras quando comparada com as jovens, possibilitando maior acúmulo de B nessa região da planta. Higashi et al. (2000) considera teores de B entre 35 e $70 \mathrm{mg} / \mathrm{kg}$ adequados para clones de eucaliptos em condições de mini e micro jardins, e valores inferiores a $20 \mathrm{mg} / \mathrm{kg}$ e superiores a $70 \mathrm{mg} /$ $\mathrm{kg}$ constituem os limites para deficiência e toxidez, respectivamente. Todos os clones apresentaram teores foliares de B inferiores a $20 \mathrm{mg} / \mathrm{kg}$ na dose de $0 \mu \mathrm{mol} / \mathrm{L}$ de B, e a máxima produção de MSPA dos clones 1270, 3336 e 3281 foi obtida com teores foliares de B superiores a $70 \mathrm{mg} / \mathrm{kg}$ (Tabela 2). Também nesses materiais foram observadas menores reduções na produção de MSPA nas maiores concentrações de B, evidenciando-se uma faixa mais ampla de utilização do B (Tabela 1).

Tabela 2 - Teores de B no tecido vegetal e teores de B estimados para máxima produção de MSPA (Ymax) dos clones de eucalipto, considerando a concentração de B na solução nutritiva.

Table 2 - B content in vegetation tissue and estimates of B content to obtain maximum production of MSPA (Ymax) of eucalyptus clones, considering boron concentration in nutrient solution.

\begin{tabular}{|c|c|c|c|c|c|c|c|c|c|}
\hline \multirow{3}{*}{$\begin{array}{l}\mathrm{B} \\
\mu \mathrm{mol} / \mathrm{L}\end{array}$} & \multicolumn{8}{|c|}{ Clones } & \multirow{3}{*}{ Média } \\
\hline & 68 & 129 & 1270 & 2486 & 3281 & 3334 & 3336 & 3487 & \\
\hline & \multicolumn{8}{|c|}{$\mathrm{mg} / \mathrm{kg}$} & \\
\hline \multicolumn{10}{|c|}{ Raízes } \\
\hline 0 & 16,54 & 22,18 & 17,78 & 18,61 & 14,48 & 17,98 & 16,49 & 18,08 & 17,77 \\
\hline 10 & 23,65 & 51,95 & 37,34 & 30,99 & 33,63 & 35,38 & 30,72 & 25,57 & 33,66 \\
\hline 20 & 78,32 & 45,71 & 50,85 & 39,66 & 52,97 & 41,23 & 54,03 & 47,42 & 51,27 \\
\hline 50 & 67,24 & 69,86 & 74,77 & 60,14 & 44,89 & 56,94 & 44,34 & 40,85 & 57,38 \\
\hline 100 & 90,43 & 89,68 & 62,41 & 64,96 & 73,94 & 76,26 & 69,56 & 55,41 & 72,83 \\
\hline$Y \max { }^{(1)}$ & 47,04 & 46,81 & 62,26 & 39,21 & 46,31 & 54,01 & 43,29 & 39,83 & 47,34 \\
\hline $\mathbf{R}^{2(2)}$ & 0,899 & 0,939 & 0,900 & 0,838 & 0,895 & 0,934 & 0,875 & 0,893 & \\
\hline \multicolumn{10}{|c|}{ Caule } \\
\hline 0 & 10,00 & 11,37 & 10,11 & 9,22 & 8,34 & 10,60 & 9,69 & 10,05 & 9,92 \\
\hline 10 & 17,34 & 15,89 & 15,54 & 13,00 & 15,88 & 13,83 & 15,28 & 13,13 & 14,99 \\
\hline 20 & 20,05 & 18,51 & 17,39 & 15,81 & 17,49 & 17,02 & 18,78 & 16,29 & 17,67 \\
\hline 50 & 21,66 & 19,69 & 17,54 & 18,25 & 17,48 & 17,87 & 18,94 & 18,17 & 18,70 \\
\hline 100 & 21,88 & 19,88 & 19,34 & 19,34 & 19,27 & 18,50 & 19,58 & 18,65 & 19,55 \\
\hline$Y_{\max }^{(1)}$ & 21,01 & 18,83 & 18,66 & 16,29 & 18,76 & 18,01 & 19,21 & 17,96 & 18,59 \\
\hline $\mathbf{R}^{2(2)}$ & 0,996 & 0,987 & 0,965 & 0,984 & 0,954 & 0,959 & 0,968 & 0,963 & \\
\hline \multicolumn{10}{|c|}{ Folhas maduras } \\
\hline 0 & 2,07 & 3,08 & 2,87 & 2,27 & 1,86 & 3,47 & 2,14 & 3,88 & 2,70 \\
\hline 10 & 45,31 & 39,53 & 57,86 & 37,29 & 57,42 & 44,09 & 46,88 & 31,09 & 44,93 \\
\hline 20 & 50,49 & 44,68 & 49,12 & 56,68 & 59,63 & 48,54 & 60,85 & 38,14 & 51,02 \\
\hline 50 & 58,75 & 48,94 & 70,52 & 72,32 & 68,81 & 55,17 & 69,40 & 46,67 & 61,32 \\
\hline 100 & 71,00 & 66,82 & 101,61 & 75,51 & 77,52 & 64,30 & 79,87 & 58,54 & 74,39 \\
\hline$Y_{\max }^{(1)}$ & 58,04 & 49,07 & 72,80 & 60,47 & 74,38 & 60,79 & 70,24 & 50,80 & 62,07 \\
\hline $\mathrm{R}^{2(2)}$ & 0,974 & 0,952 & 0,931 & 0,991 & 0,962 & 0,971 & 0,991 & 0,992 & \\
\hline \multicolumn{10}{|c|}{ Folhas jovens } \\
\hline 0 & 6,01 & 3,10 & 3,70 & 3,11 & 4,36 & 4,20 & 2,92 & 3,28 & 3,83 \\
\hline 10 & 40,21 & 34,79 & 50,29 & 31,20 & 39,30 & 29,92 & 32,24 & 26,44 & 35,55 \\
\hline 20 & 42,22 & 36,45 & 44,19 & 44,56 & 43,10 & 32,84 & 43,06 & 34,86 & 40,16 \\
\hline 50 & 49,15 & 41,86 & 54,19 & 54,25 & 47,75 & 39,78 & 46,40 & 35,18 & 46,07 \\
\hline 100 & 44,83 & 43,74 & 52,46 & 54,62 & 54,04 & 39,37 & 44,23 & 41,40 & 46,84 \\
\hline$Y_{\max }^{(1)}$ & 48,43 & 41,46 & 56,64 & 47,20 & 51,63 & 40,77 & 47,05 & 39,94 & 46,64 \\
\hline $\mathbf{R}^{2(2)}$ & 0,984 & 0,972 & 0,923 & 0,994 & 0,969 & 0,992 & 0,993 & 0,967 & \\
\hline
\end{tabular}

(1) Teor de B estimado no tecido vegetal correspondente à máxima produção de MSPA (Ymax). (2) Ajuste ao modelo de regressão raiz quadrada. ${ }^{(3)}$ Ajuste ao modelo de regressão linear, exceto clone 1270, modelo raiz quadrada; Todos os coeficientes são significativos a pelo menos $5 \%$ de probabilidade pelo test $\mathrm{t}$. 
Os clones apresentaram diferenças importantes em relação ao $\mathrm{B}$ absorvido e à sua resposta ao crescimento, por exemplo, o clone 2486 , cultivado na dose $100 \mu \mathrm{mol} / \mathrm{L}$ de B, apresentou redução de $43 \%$ na produção de MSPA com teor de B na folha madura de $75,51 \mathrm{mg} / \mathrm{kg}$, enquanto o clone 1270 , com teor de B na folha madura de 101,61, apresentou redução de apenas $16 \%$. O clone 3281 , com teor de B na folha madura de 77,52 não apresentou redução na produção de MSPA, tampouco sintomas de toxidez (Figura 2).

A eficiência na utilização dos nutrientes é um importante diferencial que deve ser considerado na avaliação nutricional e na seleção de materiais genéticos (SANTANA et al., 2002). No Tabela 3 são apresentados os CUB-B referentes aos teores estimados nos pontos de máxima produção de MSPApara cada clone. Aeficiência na utilização de B pelos clones de eucalipto obedeceu, em média, a seguinte ordem: 3487>2486>3334> 129> $1270>3336>3281>68$. Os clones 3487 e 2486 se destacaram como os de maior eficiência no uso do B, enquanto o clone 68 foi o menos eficiente.

Algumas espécies apresentam translocação de B no floema, podendo ser este importante mecanismo de tolerância à deficiência de B (BROWN e SHELP, 1997; HU et al., 1997). A concentração de B em tecidos de idades distintas dentro de uma espécie pode prover evidências da mobilidade do nutriente. A ocorrência de maior concentração de B em folhas maduras pode ser indicativo de mobilidade restrita de $\mathrm{B}$, ao passo que a maior concentração nas folhas jovens sugere mobilidade, considerando que a transpiração é menor em tecidos mais jovens. Critérios semelhantes foram adotados por Konsaeng et at. (2005), indicando que o gradiente dos teores de $\mathrm{B}$ de tecidos desenvolvidos para tecidos jovens pode ser um indicativo de remobilização de B em algumas espécies de arbóreas tropicais.

Em média, a razão B folha jovem:B folha madura foi de 0,74 e 1,29 sob condições adequadas e deficientes em B, respectivamente (Tabela 3). Essa inversão do gradiente entre folhas jovens e maduras pode ser um indicativo da redistribuição do B em eucalipto. Resultados semelhantes foram obtidos por Al-Molla (1986), Marentes et al. (1996) e Shelp et al. (1992a) nas culturas de soja e brócolis. Se o B fosse móvel apenas no xilema, a sua concentração nos tecidos maduros tenderia a ser sempre maior.

Embora a avaliação do gradiente de concentração entre os tecidos forneça informações importantes da mobilidade do B nas plantas, devem-se considerar as mudanças nos componentes da matéria seca decorrentes da idade do tecido. Avaliações mais confiáveis devem ser suportadas por técnicas de detecção mais precisas, a exemplo da utilização de isótopos de B (SAH e BROWN, 1997).

Tabela 3 - Coeficiente de utilização biológico de B (CUB-B) e razão dos teores de B no tecido vegetal, correspondentes aos teores referentes à máxima produção de MSPA (adequado) e aos teores na dose de $0 \mu$ mol/L de B (deficiente).

Table 3 - B nutrient use efficiency $(N U E-B)$ and $B$ content ratio in vegetation tissue, considering $B$ content to obtain the maximum shoot dry matter production (MSPA)(adequate) and B content correspondent to $O \mu m o l / L$ de B (deficiency).

\begin{tabular}{|c|c|c|c|c|c|c|c|c|c|c|}
\hline \multirow[t]{2}{*}{ Característic } & \multicolumn{9}{|c|}{ Clones } & \multirow[b]{2}{*}{ Média $^{(1}$} \\
\hline & 68 & 129 & 1270 & 2486 & & 281 & 3334 & 3336 & 3487 & \\
\hline \multicolumn{11}{|c|}{ CUB-B $^{(2)}(\mathrm{kg} / \mathrm{kg})$} \\
\hline Raiz & 21259 & 21363 & 16062 & 25501 & & 594 & 18516 & 23102 & 25110 & 21563 \\
\hline Caule & 47603 & 53112 & 53601 & 61401 & & 313 & 55535 & 52046 & 55675 & 54036 \\
\hline F. maduras & 17228 & 20379 & 13736 & 16537 & & 445 & 16451 & 14237 & 19684 & 16462 \\
\hline F. jovens & 20647 & 24122 & 17655 & 21187 & & 369 & 24526 & 21254 & 25035 & 21724 \\
\hline Média $^{(3)}$ & 22709 & 29084 & 28162 & 32082 & & 294 & 30304 & 27398 & 34317 & 28919 \\
\hline \multirow[t]{2}{*}{$\operatorname{Razão}^{(4)}$} & Status de B & \multicolumn{8}{|c|}{ clones } & \\
\hline & & 68 & 129 & 1270 & 2486 & 3281 & 3334 & 3336 & 3487 & Média ${ }^{(1)}$ \\
\hline \multirow[t]{2}{*}{ FJ:FM } & Adequado & 0,83 & 0,84 & 0,78 & 0,78 & 0,69 & 0,67 & 0,67 & 0,79 & 0,74 \\
\hline & Deficiente & 1,58 & 1,06 & 1,14 & 1,44 & 1,76 & 0,95 & 1,53 & 0,85 & 1,29 \\
\hline \multirow[t]{2}{*}{ FJ: caule } & Adequado & 1,90 & 2,12 & 2,14 & 2,45 & 2,13 & 2,22 & 2,08 & 2,22 & 2,16 \\
\hline & Deficiente & 0,33 & 0,29 & 0,32 & 0,36 & 0,39 & 0,31 & 0,34 & 0,33 & 0,33 \\
\hline \multirow[t]{2}{*}{ FJ: raízes } & Adequado & 0,85 & 0,85 & 0,64 & 1,02 & 0,86 & 0,74 & 0,92 & 1,00 & 0,86 \\
\hline & Deficiente & 0,20 & 0,15 & 0,18 & 0,18 & 0,23 & 0,18 & 0,20 & 0,18 & 0,19 \\
\hline
\end{tabular}

${ }^{(1)}$ Média dos clones. ${ }^{(2)}$ CUB-B baseados nos teores estimados de B no tecido vegetal referentes à máxima produção de MSPA. ${ }^{(3)}$ Média ponderada dos valores correspondentes a máxima produção de matéria seca. ${ }^{(4)}$ FJ: folhas jovens e FM: folhas maduras.

R. Árvore, Viçosa-MG, v.33, n.5, p.821-830, 2009 
Em média, a razão de teores de B folha jovem:B caule foi de 0,33 e 2,16 e B folha jovem:B raiz de 0,19 e 0,86 sob condição de deficiência e suprimento adequado de $\mathrm{B}$, respectivamente (Tabela 3 ). A distribuição de B nos tecidos vegetais foi largamente influenciada pelo status do nutriente. Em condição de deficiência de B, a distribuição para folhas e meristemas apical do caule foi prejudicada, com maior acúmulo nas raízes e nos caules.

Os resultados indicaram, portanto, distinta adaptação dos clones tanto para deficiência quanto para toxidez de B. As características de cada material genético devem ser consideradas para a alocação dos clones nas áreas de plantio, tornando mais eficiente o sistema de produção. Assim, a utilização de clones mais tolerantes à deficiência de $\mathrm{B}$ é alternativa importante para o cultivo de eucalipto em áreas onde é comum a deficiência do nutriente, como no Cerrado brasileiro. Outros materiais genéticos, de elevada produtividade e supostamente sensíveis à deficiência de B, poderão adaptar-se melhor em áreas onde a fertilização com B é parte integral do programa de fertilização.

\section{CONCLUSÕES}

1. A resposta do eucalipto ao B na solução nutritiva depende do clone, havendo diferenças entre eles na tolerância à deficiência e toxidez e na eficiência de utilização de B.

2. Três clones testados apresentam alta sensibilidade à deficiência de $\mathrm{B}$ e dois foram tolerantes.

3. Um clone apresentou alta tolerância à toxidez por B.

4. Dois clones destacaram-se na eficiência de utilização de B.

\section{AGRADECIMENTOS}

À CAPES/CNPq e À FAPEMIG pelo apoio financeiro.

\section{REFERÊNCIAS}

ANDRADE, S. C. et al. Exigencia y distribución de boro en plantas de eucalipto. Bosque, v.16, n.1, p.53-59, 1995.
ASAD, A.; BELL, R. W.; DELL, B. A critical comparison of the external and internal boron requirements for contrasting species in boronbuffered solution culture. Plant Soil, v.233, n.1, p.31-45, 2001.

BELL, R. W. Diagnosis and prediction of boron deficiency for plant production. Plant Soil, v.193, p.149-168, 1997.

BLEVINS, D. G.; LUKASZEWSKI, K. M. Boron in plant structure and function. Annual ReviewPlant Physiology Plant Molecular Biology, v.49, p.481-500, 1998.

BROWN, P. H.; SHELP, B. J. Boron mobility in plants. Plant Soil, v.193, n.1, p.85-101, 1997.

CAKMAK, I.; RÖMHELD, V. Boron deficiencyinduced impairments of cellular functions in plants. Plant Soil, v.193, n.1, p.71-83, 1997.

CLARK, R. B. Characterization of phosphate of intact maize roots. Journal of Agricultural and Food Chemistry, v.23, p.458-460, 1975.

CLARKSON, D. T. et al. Root hydraulic conductance: diurnal aquaporin expression and the effects of nutrient stress. Journal Experimental of Botany, v.51, n.1, p.61-70, 2000.

DANNEL, F.; PFEFFER, H.; RÖMHELD, V. Compartmentation of boron in roots and leaves of sunflower as affected by boron supply. Journal Plant Physiology, v.153, p.615-622, 1998.

DECHEN, A. R.; HAAG, H. P.; CARMELLO, Q. A. Funções dos micronutrientes nas plantas. In: FERREIRA, M. E.; CRUZ, M. C. P., (Eds.) Micronutrientes na agricultura. Piracicaba: POTAFOS/CNPq, 1991. p.65-78.

HIGASHI, E. N.; SILVEIRA, R. L. V. A.; GONCALVES, A. N. Propagação vegetativa de Eucalyptus: Princípios básicos e a sua evolução no Brasil. Piracicaba: IPEF, 2000. v.192. p.1-11. (Circular Tecnica IPEF)

R. Árvore, Viçosa-MG, v.33, n.5, p.821-830, 2009 
HU, H.; BROWN, P. Absorption of boron by plant roots. Plant Soil, v.193, NUMERO, p.49-58, 1997.

HU, H.; BROWN, P. H.; LABAVITCH, J. M. Species variability in boron requirements is correlated with cell wall pectin. Journal Experimental Botany, v.47, p.227-232, 1996.

KONSAENG, S.; DELL, B.; KERKASEM, B. A survey of wood tropical species for boron retranslocation. Plant Production Science, v.8, p.338:341, 2005.

KOZLOWSKI, T. T.; PALLARDY, S. G. Physiology of woody plants. 2.ed. San Diego: Academic Press, 1997. 411p.

LI, C. J. et al. Effects of boron starvation on boron compartmentation, and possibly hormonemediated elongation growth and apical dominance of pea (Pisum sativum) plants. Physiologia Plantarum, v.111, p.212-219, 2001.

NABLE, R. O.; BAÑUELOS, G. S.; PAULL, J. G. Boron toxicity. Plant Soil, v.198, NUMERO, p.181-198, 1997.

NOVELINO, J. O. et al. Efeito dos níveis de boro no crescimento de Eucalyptus sp. Revista Árvore, v.6, n.1, p.45-51, 1982.

PERKASEM, B.; JAMJOD, S. Genotypic variation in plant response to low boron and implications for plant breeding. Plant Soil, v.193, p.169-180, 1997.
SAH, R. N.; BROWN, P. H. Techniques for boron determination and their application to the analysis of plant and soil samples. Plant Soil, v.193, n.1, p.15-33, 1997.

SAKYA, A. T.; DELL, B.; HUANG, L. Boron requirements for Eucalyptus globulus seedlings, Plant Soil, v.246, n.1, p.87-95, 2002.

SANTANA, R. C.; BARROS, N. F.; NEVES, J. C. L. Eficiência de utilização de nutrientes e sustentabilidade da produção em procedências de eucalyptus grandis e eucalyptus saligna em sítios florestais do estado de São Paulo. Revista Árvore, v.26, p.447-457, 2002.

SAS Institute. SAS/STAT 9.1 User's guide. Cary: 2004.

SGARBI, F.; SILVEIRA, R. L. V. A. Resposta do Eucalyptus à aplicação de boro e potássio na região de Três Marias-MG. In: SIMPÓSIO SOBRE O USO DO BORO EM FLORESTAS DE

EUCALIPTO, 2., 1998, Piracicaba. Anais.

Piracicaba: IPEF; ESALQ, 1999. p.89-105.

SHARMA, P. N.; RAMCHANDRA, T. Water relations and photosynthesis in mustard plants subjected to boron deficiency. Indian Journal Plant Physiology, v.33, p.150-154, 1990.

TAIZ, L.; ZEIGER, E. Fisiologia vegetal. 3.ed. Porto Alegre: Artmed, 2004. 719p. 